\title{
INTERNATIONAL JOURNAL OF 3-D INFORMATION MODELING
}

January-March 2012, Vol. 1, No. 1

\section{Table of Contents}

\section{Research Articles}

1 BIM-Based Life-Cycle Management for Reinforced Concrete Buildings André Borrmann, Technische Universität München, Germany

Katharina Lukas, Technische Universität München, Germany

Marc Zintel, Technische Universität München, Germany

Peter Schießl, Ingenieurbüro Schießl Gehlen Sodeikat, Germany

Michael Kluth, Consultant, Germany

25 Indoor Spatial Information

Stephan Winter, The University of Melbourne, Australia

43 Improving Interoperability of 3D Geographic Features via Geographic Managed Objects

Jaume Dominguez Faus, Aalborg University, Denmark

Wan Wen, Aalborg University, Denmark

55 Building Information Modelling (BIM) for Facilities Management (FM): The Mediacity Case Study Approach

Yusuf Arayici, University of Salford, UK

Timothy Onyenobi, University of Salford, UK

Charles Egbu, University of Salford, UK 


\title{
Building Information Modelling (BIM) for Facilities Management (FM): The Mediacity Case Study Approach
}

\author{
Yusuf Arayici, University of Salford, UK \\ Timothy Onyenobi, University of Salford, UK \\ Charles Egbu, University of Salford, UK
}

\begin{abstract}
Facilities Management (FM) as the total management of all services supports the core businesses of an organisation in a building. However, today's buildings are increasingly sophisticated and the need for information to operate and maintain them is vital. Facility Managers have to acquire, integrate, edit, and update diverse facility information ranging from building elements, fabric data, operational costs, contract types, room allocation, logistics, maintenance, etc. However, FM professionals face challenges resulting in cost and time related productivity, efficiency and effectiveness losses. Building Information Modelling (BIM), that seeks to integrate the building lifecycle, can provide improvements and help to overcome those challenges. Thus, the paper explores how BIM can contribute to and improve the FM profession. It uses the MediaCityUK project as a case study, which is a regeneration project aiming to attract media institutions locally and worldwide and establish itself as an international centre for excellence. For this purpose, the key FM tasks are identified and a BIM model for the new university building in MediaCityUK is developed and experimented with the FM tasks by a group of FM experts. As a result, the paper explains how BIM can support FM tasks in an itemised manner.
\end{abstract}

Keywords: $\quad$ BuildingInformation Modelling, Building Maintenance, Facilities Management, MediaCityUK, Operational Building Lifecycle, Space Management

\section{INTRODUCTION}

Building Information Modelling (BIM) as a lifecycle evaluation concept seeks to integrate processes throughout the entire lifecycle of a building. It aims to provide a more streamlined

DOI: $10.4018 / \mathrm{ij} 3 \operatorname{dim} .2012010104$ business process, associated project and site management methodologies including complete facilitation of construction knowledge during the full lifecycle of a building (Kymell, 2008). The focus is to create and reuse consistent digital information by the stakeholders throughout the lifecycle. BIM in most simple terms is the utilization of a database infrastructure to encap- 
sulate built facilities with specific viewpoints of stakeholders (Arayici et al., 2009). It is a methodology to integrate digital descriptions of all the building objects and their relationships to others in a precise manner, so that stakeholders can query, simulate and estimate activities and their effects of the building process as a lifecycle entity (Gillard et al., 2008).

BIM incorporates a methodology based around the notion of collaboration between stakeholders using ICT to exchange valuable information throughout the lifecycle. Such collaboration is seen as the answer to the fragmentation that exists within the building industry and has caused various inefficiencies (Jordani, 2008) and it has come to a point where change is now eminent (NBIMS, 2007) because BIM can provide the required valued judgments that create more sustainable infrastructures to satisfy owners and occupants. However, it is necessary to realize that while the users and owners can change over the lifecycle of a building within different intervals, the most important aspect is to minimize the impact to the natural environment. While this can be achieved in a variety of ways using maturated BIM integrated construction methodologies, they are not discussed here due to our specific focus on facilities management.

The paper aims to explore and experiment BIM for FM using the MediaCity project, where the University of Salford will have an existence in MediaCity for the conduit of Higher Education, in order to identify the extent to BIM can contribute to the facilities management (Building Maintenance, Building use Management).

\section{FACILITIES MANAGEMENT (FM) PRACTICE AND CHALLENGES}

Facilities Management is a multi-disciplinary field encompassing multi-disciplines to ensure the functionality of built environment by integrating people, place, process and technology (Cotts et al., 2009). In scenarios such as major relocation of organisations into new buildings,
FM for the building lifecycle is the key aspects that should be conducted effectively and efficiently (Nazali et al., 2009). However, there are key challenges in the current practice such as building operational life cycle management, some of which revolves around information collection retrieval and sharing (Cardellino \& Finch, 2006). The challenges in FM are revealed more when the information exchange challenges are experienced during design/construction are multiplied across the lifecycle of a facility (Jordani, 2010).

There is a need for optimising the building use from an FM point of view for effective and efficient building lifecycle management. $85 \%$ of the lifecycle cost of a facility occurs after construction is completed and the NIST (National Institute of Standards and Technology) Interoperability Study indicated that two-thirds of the estimated cost is lost in the US due to inefficiencies during operations and maintenance phases (Jordani, 2010; Rundell, 2006). The maintenance requirements of a building (hard issues) (Olomolaiye et al., 2004) such as maintenance of window and doors require a managed approach due to the size of the facility. It is also important to identify designed and actual occupant functions (soft issues) (Olomolaiye et al., 2004) and allocate spaces during the building life cycle for operational efficiency. Space reallocation is a consideration that should not be overlooked as the functional requirement of the owner/user may change in time that also underscores building life cycle management. Adetailed list of FM tasks against which benefits from BIM is discussed later in the paper.

Rundell (2006) suggested that owners and operators can mitigate their portion of the cost by using the high-quality building information from a BIM design process during the longer, more expensive maintenance and operation phase of the building's lifecycle, while Azhar et al. (2008) states that BIM may allow facility managers to enter the decision-making process at a much earlier stage, where they can influence the design and construction. 
Best practice projects of BIM for facilities management such as Sydney Opera House (CRC, 2007; Mitchell, 2005), the Atlantic College (Gillard et al., 2008) projects provided some evidence of gains and benefits from BIM use. Some key benefits are:

- Accurate geometrical representation of the parts of the building,

- Faster and more effective information sharing,

- More predictable environmental performance and life cycle costing,

- Better production quality - documentation output is flexible and exploits automation,

- Ensuring that procurement decisions are made on the basis of whole-life costs, cultural fit and not solely short term financial criteria,

- $\quad$ Ensuring that purchasing will be coordinated between departments where possible.

However, there is still lack of clear evidence on whether and how BIM could benefit decision-making in facilities management task by task. That is to say, despite acting as a data pool, more benefits from BIM for facilities are still to be clarified and explained in an itemised way. This issue should be explored and assessed through real projects. The following section introduces the MediaCity project, which is the case study of BIM experimentation for the FM tasks and challenges.

\section{THE MEDIACITYUK PROJECT}

MediaCityUK is a purpose-built creative and media development in Salford Quays, Manchester, UK. It aims to bring together companies from across the sector and establish an international centre for excellence in the digital media and creative industries (Wylie, 2007). The University of Salford will be an occupant of a building in Mediacity, comprising 100,000 sq $\mathrm{ft}$ over four floors which will be linked to the University's three colleges on the main campus at Peel Park (Russell, 2009). It is also projected that over 4,500 staff and students and some key research and business support units would move to Mediacity. The University's centre at MediaCityUK includes a broadcast zone, digital media zone, virtual laboratory, digital performance space and creative spaces for use in academic teaching, project-based learning and user-centred design and innovation (Russell, 2009).

Owing to the importance of the move by some departments in the University to Media City, there is the need for FM (Cardello \& Finch, 2006) in relation to relocation and operational building lifecycle management, which need a careful and planned process to save time and cost and to minimise adverse environmental, social impacts. Relocation will involve movement of light and heavy equipments; furniture will be moved from the exiting to new building. Personnel and students relocation exercise will also take place as staff and students will begin using the facilities from September 2011.

In the following section, the paper explains the research methodology adopted in the paper.

\section{RESEARCH METHODOLOGY}

The aim is to investigate how BIM can support effective and efficient conduct of FM tasks using the university building in MediaCityUK as the case study with particular focus on i) how BIM contributes to maintenance operations (Hard FM) of the MediaCityUK facility, ii) how BIM can contribute to the space management (Soft FM) of the MediaCityUK facility during the relocation and operational lifecycle management of the building following the move.

The case study oriented qualitative research for discovery, comparison, and experimentation is employed as it has experimental factors through the MediaCity project. The adopted single case study research method included literature review, interviews and BIM model development for data collection, and concept mapping and experimentation methods for data analysis. In addition to the literature findings, semi-structured interviews with experts helped 
Figure 1. The case study protocol

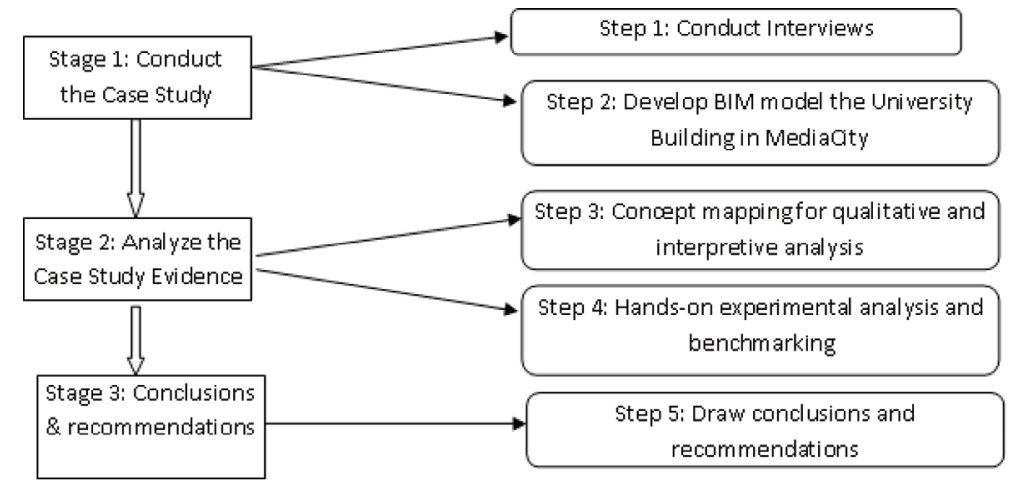

to finalise the FM tasks before the BIM experimental analysis. Figure 1 depicts the case study protocol that is identified with the considerations given to construct validity, internal validity, external validity and reliability in the research.

An empirical investigation of a contemporary phenomenon within its real-life context is one situation in which case study methodology is applicable. The following five components (Yin, 2003) were used for the review of the case study protocol in the research.

1. A study's questions,

2. Its propositions,

3. Its unit(s) of analysis,

4. The logic linking the data to the propositions, and

5. The criteria for interpreting the findings

The research questions framed as "who", "what", "where", "how", and "why" determine the relevant strategy to be used and the nature of the "how" questions in the paper lead to an explanatory case study strategy to propose efficiency gains and improvements in the conduct of FM activities in relation to the university building in Mediacity. The unit of analysis in the case study is BIM. The linking of the data to the propositions and the criteria for interpretation of the findings are represented in the data analysis section of the paper.

The following section explains the stages in Figure 1 respectively.

\section{CONDUCT THE CASE STUDY DATA COLLECTION: INTERVIEWS AND THE BIM MODEL DEVELOPMENT}

Two semi-structured interviews were carried out with experts in Facilities Management and Information Technology areas to explore and analyse particular perspectives, key tasks, and challenges in FM and to identify the potential benefits of BIM for FM. Further, two more interviews were carried out with the FM manager of the university and with the MediaCityUK Director, who has responsibilities for the university in the MediaCity project to explore the FM challenges and tasks in relation to the case study context. The interview questions ranged from the key tasks and the level of IT applications in those FM tasks, difficulties and challenges, to anticipated benefits and drawbacks of application of BIM in FM for the university building in the MediaCityUK project. Findings were analysed via concept mapping and informed the analysis of the actual BIM experimentation.

The BIM Master model of the university building in MediaCity was developed from the architectural and engineering documents which can be divided into sub models such as Architecture, Land Use, Terrain, Utilities, Structure Mechanical Electrical, Transportation, Equipment, and Civil. Building model data shall comply with Revit DWG, DXF and IFC interoperable file format. 
Figure 2. Spatial hierarchy: - LZ: Building position on site, FS: Spaces identified by functions, RM: Wall bounded spaces, PL: Local areas within a room

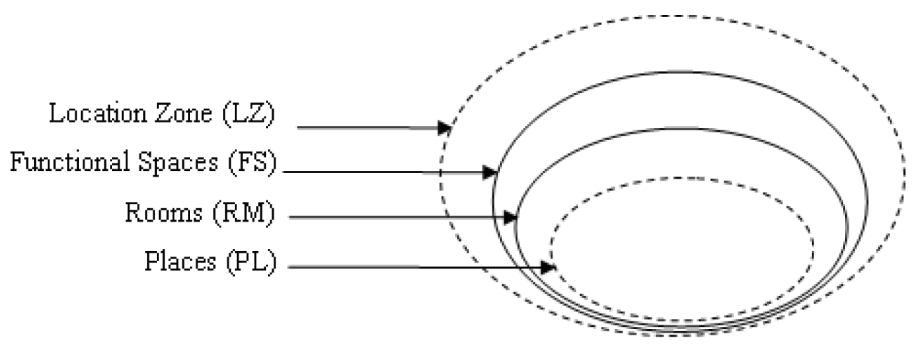

The BIM model has spatial definitions such as: Location Zones, Functional Spaces, Rooms and Places, a form of hierarchical space classification from largest (building site) to smallest (places within a room). This helps in understanding the spaces (Figure 2 and Figure 3).

Table 1 generated from the BIM model shows the storeys of the building in MediaCity.

Further, functional spaces in the building are generated from the BIM Model automatically (Table 2).

The schedules of the rooms in the first four floor of the building are also generated from the BIM in Table 3.

As spaces for the University of Salford are located in the first four floors, spatial analysis is carried out for these floors only.

\section{ANALYSIS OF THE CASE STUDY EVIDENCE}

This section discusses the findings from the interviews and BIM model development via concept mapping and hands-on experimentation against the key FM tasks.

\section{BIM for Facilities Management}

The main highlight from the interview with the FM expert was the importance of space planning in FM, especially as it relates to the
MediaCityUK building. However, the focus was more on the current industry standard FM tools in comparison to BIM. The interviewee emphasised that Computer Aided FM (CAFM) is a very key tool in FM and has been around much longer than BIM. Therefore, BIM should prove itself more beneficial for FM than CAFM. The concept map in Figure 4, which is developed from the interview findings with the FM expert, captures the related issues of FM and BIM.

An inspection of Figure 4 shows that both CAFM and BIM can provide some benefits to FM functions. The major difference between BIM and CAFM is that the CAFM has no need for libraries unlike the BIM model. The interviewee highlighted that BIM will offer some benefits in FM but underscored an important factor which emphasizes on the expertise involved in the creation and maintenance of the BIM model. The model needs to be consistently populated and updated and the benefit which can be ultimately derived from the BIM model will depend on the quality of the model maintenance.

According to the interviewee, the application ofFM principles to the MediaCityUK building will be no different from its application to many modern offices to try to meet very diverse requirements and very high energy demands for a 24/7 operation. Without much emphasis on BIM, the FM expert concluded that IT application in FM will provide good benefits. 
Figure 3. 3D and plan views from the BIM model development
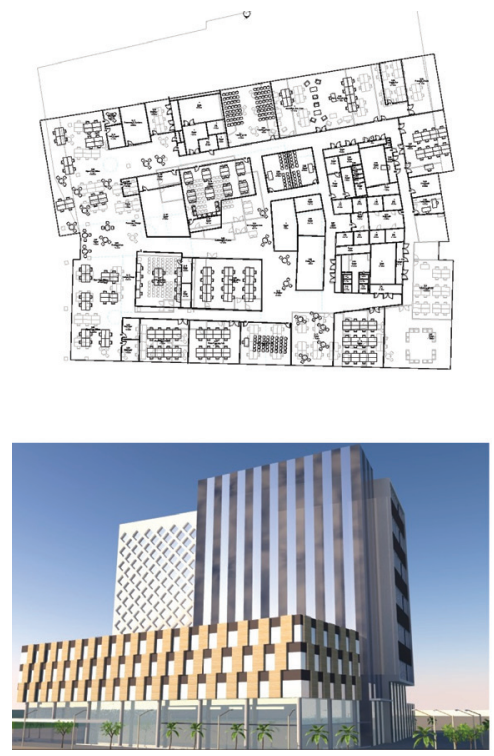

\section{BIM Integration with Virtual Reality (VR)}

The interviewee, who provided information about BIM and IT issues, was an expert in Virtual Reality development and implementation for the built environment applications. At the time of the interview, they were involved in the development of a virtual reality model of the whole MediaCityUK buildings in collaboration with the University of Salford and commented extensively on the adopted approach. The concept map in Figure 5, which was developed from the findings of the interview with the VR expert, captures the related issues of VR and BIM.

The University was involved in generating an immersible VR prototype of the MediaCityUK buildings for reasons such as community engagement, international visitor presentations, problem solving, and university promotion. The VR model had an appealing front end with no database. The model generation process encountered difficulties such as errors in architectural drawings used for model generation and stakeholder amendments which resulted in extended completion time.
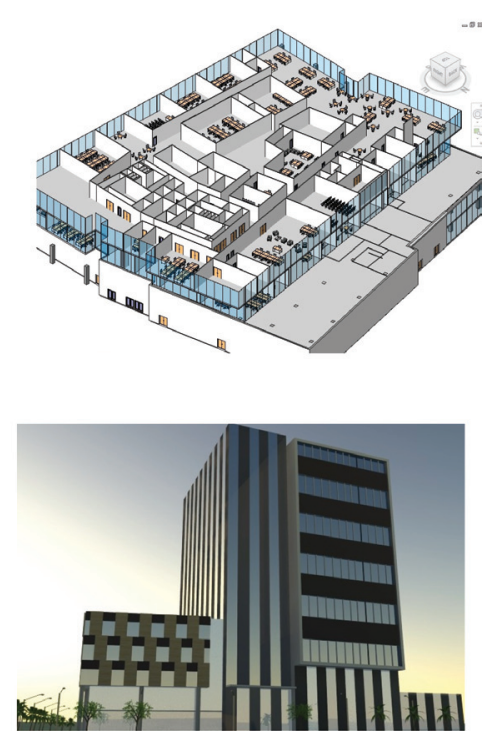

The VR model according to the VR expert is less accurate than BIM models because a games engine is also used in the development of the VR model. However, the reality element of the VR model according to the interviewee can work in synergy with the BIM extensive database and accuracy to produce an all in one tool which can benefit FM especially with regards to visual space planning and data storage and retrieval for FM purpose.

\section{Challenges and Insight of FM for the University Facilities Management}

An interview with the Estate Manager of the University allowed useful information to be gathered on the required FM strategy. The choices of an extension of FM services for the facilities in the main campus to the MediaCityUK and the provision of a different FM services model for the new facility in MediaCity is elaborated in the interview. The concept map in Figure 6, which was developed from the findings of the interview with the university Estate Manager, captures the challenges and insight of FM for the university. 
Table 1. Storeys settings generated from the BIM model

\begin{tabular}{|c|c|c|c|}
\hline $\begin{array}{l}\text { Level } \\
\text { Code }\end{array}$ & $\begin{array}{l}\text { Meters } \\
\text { Above }\end{array}$ & Level Name & Elevation in Meters \\
\hline Level - G & +24.45 & $\begin{array}{l}\text { Ground Floor Level: University of Salford (Studios, Labora- } \\
\text { tories and unassigned spaces) }\end{array}$ & 24.45 \\
\hline Level - 01 & +28.45 & $\begin{array}{l}\text { First Floor Level: University of Salford (Studios, Laboratories, } \\
\text { offices and unassigned spaces) }\end{array}$ & 28.45 \\
\hline Level - 02 & +32.65 & $\begin{array}{l}\text { Second Floor Level: University of Salford (Studios, Labora- } \\
\text { tories, offices and unassigned spaces) }\end{array}$ & 32.65 \\
\hline Level - 03 & +36.65 & $\begin{array}{l}\text { Third Floor Level: University of Salford Open plan, exhibition, } \\
\text { offices, meeting and multi-function areas }\end{array}$ & 36.65 \\
\hline Level - 04 & +40.65 & Fourth Floor Level & 40.65 \\
\hline Level - 05 & +44.65 & Fifth Floor Level & 44.65 \\
\hline Level - 06 & +48.65 & Sixth Floor Level & 48.65 \\
\hline Level - 07 & +52.65 & Seventh Floor Level & 52.65 \\
\hline Level - 08 & +56.65 & Eight Floor Level & 56.65 \\
\hline Level - 09 & +60.65 & Ninth Floor Level & 60.65 \\
\hline Level - 10 & +64.65 & Tenth Floor Level & 64.65 \\
\hline Level - 11 & +68.65 & Eleventh Floor Level & 68.65 \\
\hline Level - 12 & +72.56 & Twelfth Floor Level & 72.56 \\
\hline Level - 13 & +76.65 & Plant Floor Level & 76.65 \\
\hline Level - 14 & +80.65 & Roof Level & 80.65 \\
\hline Level - 15 & +82.65 & Roof Top & 82.65 \\
\hline
\end{tabular}

Table 2. Functional spaces of the building identified and generated from the BIM model

\begin{tabular}{|l|l|l|}
\hline FS Code & FS Name & FS Definition \\
\hline G.18 & Living Laboratory & $\begin{array}{l}\text { Living laboratory, ceiling, columns, elliptical wall and multi } \\
\text { use area. }\end{array}$ \\
\hline G.02 & Circulation/Exhibition & $\begin{array}{l}\text { Relaxed seating area, access to lifts, green room and stairs } \\
\text { to first floor. }\end{array}$ \\
\hline 1.04 & Collaboration Meeting Area & $\begin{array}{l}\text { Common open seating area, balusters overlooking ground } \\
\text { floor, bridge to studio rooms. }\end{array}$ \\
\hline 2.21 & Vend Breakout & Kitchen, kitchen storage, seating area, resource area. \\
\hline 2.04 & Collaborative Space & Relaxed seating area, access to lifts lobby and stairs. \\
\hline 2.08 & Open Plan Office & Breakout area, locker storage, columns, curtain walls. \\
\hline 3.26 & News Room Workshop & Journalism resource area, relaxed seating area. \\
\hline 3.03 & Collaborative Space & $\begin{array}{l}\text { Resource area, relaxed seating area, exhibition, access to } \\
\text { lifts lobby and stairs. }\end{array}$ \\
\hline 2.08 & Open Plan Office & Breakout area, locker storage, resource storage, columns. \\
\hline
\end{tabular}


Table 3. The room schedule of the building for the first four floors

\begin{tabular}{|c|c|c|c|c|c|c|c|}
\hline ID & $\begin{array}{l}\text { Types } \\
\text { Ground Flr. }\end{array}$ & ID & $\begin{array}{l}\text { Types } \\
\text { First Flr. }\end{array}$ & ID & $\begin{array}{l}\text { Types } \\
\text { Second Flr. }\end{array}$ & ID & $\begin{array}{l}\text { Types } \\
\text { Third Flr. }\end{array}$ \\
\hline G.01 & $\begin{array}{l}\text { University Lift } \\
\text { Lobby }\end{array}$ & 1.01 & Lift Lobby & 2.01 & & 3.01 & Lift Lobby \\
\hline G.02 & $\begin{array}{l}\text { Circulation/ } \\
\text { Exhibition }\end{array}$ & 1.02 & $\begin{array}{l}\text { Circulation } \\
\text { Breakout }\end{array}$ & 2.02 & Circulation & 3.02 & Circulation \\
\hline G.03 & & 1.03 & Stair & 2.03 & Stairs & 3.03 & Collaborative Space \\
\hline G.04 & Lobby & 1.04 & $\begin{array}{l}\text { Collaboration/ } \\
\text { Meeting Area }\end{array}$ & 2.04 & Collaborative Space & 3.04 & Breakout area \\
\hline G.05 & Reception & 1.05 & $\begin{array}{l}\text { Ops Manage- } \\
\text { ment FM Office }\end{array}$ & 2.05 & Breakout Area & 3.05 & Open Plan Office \\
\hline G.06 & - & 1.06 & Cleaner & 2.06 & & 3.06 & \\
\hline G.07 & Security & 1.07 & Bridges & 2.07 & Pod & 3.07 & Study \\
\hline G.08 & Mail & 1.08 & Lobby & 2.08 & Open Plan Office & 3.08 & Hot Room \\
\hline G.09 & $\begin{array}{l}\text { Primary IT Sys- } \\
\text { tems }\end{array}$ & 1.09 & $\begin{array}{l}\text { Radio Control } \\
\text { Room }\end{array}$ & 2.09 & & 3.09 & Hot Room \\
\hline G. 10 & Exhibition & 1.1 & Radio Studio A & 2.1 & Hot Room & 3.1 & Technician Support \\
\hline G.11 & - & 1.11 & Radio Studio B & 2.11 & Hot Room & 3.11 & Teaching Lab \\
\hline G.12 & Servery & 1.12 & Sec IT & 2.12 & Hot Room & 3.12 & $\begin{array}{l}\text { Secondary IT Sys- } \\
\text { tems }\end{array}$ \\
\hline G.13 & Storage/Prep & 1.13 & TV Control B & 2.13 & Hot Room & 3.13 & Lockers/Storage \\
\hline G.14 & $\begin{array}{l}\text { House Keeping } \\
\text { Storage }\end{array}$ & 1.14 & Rack Room & 2.14 & $\begin{array}{l}\text { Secondary IT Sys- } \\
\text { tems }\end{array}$ & 3.14 & Kitchen \\
\hline G.15 & Furniture Store & 1.15 & $\begin{array}{l}\text { DPL Control } \\
\text { Room }\end{array}$ & 2.15 & Lockers/Storage & 3.15 & Exhibition \\
\hline G.16 & Store & 1.16 & Store & 2.16 & PC Suite 1 & 3.16 & Vend Breakout \\
\hline G.17 & Green Room & 1.17 & DPL Lobby & 2.17 & AV Store & 3.17 & \\
\hline G.18 & $\begin{array}{l}\text { Living Labora- } \\
\text { tory }\end{array}$ & 1.18 & $\begin{array}{l}\text { DPL Control } \\
\text { Room }\end{array}$ & 2.18 & Teaching 3 & 3.18 & Project Room \\
\hline G.19 & DPL Dressing & 1.19 & $\begin{array}{l}\text { D P L Con - } \\
\text { trol Room } \\
\text { A (Sound) }\end{array}$ & 2.19 & Dubbing Theatre & 3.19 & Store \\
\hline G.20 & Media Store & 1.2 & Lobby & 2.2 & Music Comp. Suite & 3.2 & Store \\
\hline G.21 & Lobby & 1.21 & Lobby & 2.21 & Vend/Breakout & 3.21 & Store \\
\hline G.22 & $\begin{array}{l}\text { Digital Media } \\
\text { Perfor. Lab. }\end{array}$ & 1.22 & & 2.22 & Cleaner & 3.22 & PC Suite 2 \\
\hline G. 23 & - & 1.23 & & 2.23 & Teaching Playback & 3.23 & Meeting 1 \\
\hline G.24 & DPL Store & 1.24 & & 2.24 & $\begin{array}{l}\text { Channel M Produc- } \\
\text { tion }\end{array}$ & 3.24 & Multi-Faith Room \\
\hline G. 25 & $\begin{array}{l}\text { Tech Support Of- } \\
\text { fice/IT }\end{array}$ & 1.25 & & 2.25 & Edit Suite 1 & 3.25 & $\begin{array}{l}\text { Seminar Area for } \\
\text { Video Editing Suite }\end{array}$ \\
\hline G.26 & $\begin{array}{l}\text { TV Overspill } \\
\text { Store }\end{array}$ & 1.26 & & 2.26 & Edit Suite 2 & 3.26 & $\begin{array}{l}\text { Newsroom/ } \\
\text { Workshop }\end{array}$ \\
\hline
\end{tabular}

continued on following page 


\section{Table 3. continued}

\begin{tabular}{|c|c|c|c|c|c|c|}
\hline G.27 & Lobby & 1.27 & 2.27 & Edit Suite 3 & 3.27 & U.C.M.M.R.L \\
\hline G.28 & TV Studio B & 1.28 & 2.28 & Library & 3.28 & $\begin{array}{l}\text { Video Processing } \\
\text { Lab. }\end{array}$ \\
\hline G.29 & TV Studio A & 1.29 & 2.29 & ILS Staff & 3.29 & Hot Room \\
\hline G.30 & TV Studio Store & 1.3 & 2.3 & Quiet Study 1 & 3.3 & Hot Room \\
\hline G.31 & - & 1.31 & 2.31 & Server & 3.31 & Teaching 1 \\
\hline \multirow[t]{19}{*}{2.32} & Staff Area & 1.32 & 2.32 & $\begin{array}{l}\text { Secondary IT Sys- } \\
\text { tems }\end{array}$ & 3.32 & Teaching 2 \\
\hline & & & 2.33 & Meeting 2 & 3.33 & $\begin{array}{l}\text { Resource/ } \\
\text { Storage }\end{array}$ \\
\hline & & & 2.34 & Teaching 4 & 3.34 & \\
\hline & & & 2.35 & Lecture Room & 3.35 & Teaching Room \\
\hline & & & 2.36 & $\begin{array}{l}\text { Audio Post-Produc- } \\
\text { tion }\end{array}$ & 3.36 & Store \\
\hline & & & 2.37 & Lobby & 3.37 & \\
\hline & & & 2.38 & Sound Booth & 3.38 & Video Editing Suite \\
\hline & & & 2.39 & Technician Support & 3.39 & Control Room \\
\hline & & & 2.4 & Lobby & 3.4 & Msc Student Space \\
\hline & & & 2.41 & Media Tech Lab & 3.41 & Future Expansion \\
\hline & & & 2.42 & Store & 3.42 & $\begin{array}{l}\text { Computer Teaching } \\
\text { Area }\end{array}$ \\
\hline & & & 2.43 & Store & 3.43 & Cleaner \\
\hline & & & 2.44 & Kitchen & 3.44 & Live Booth \\
\hline & & & 2.45 & Store & 3.45 & Teaching Office \\
\hline & & & 2.46 & Lobby & 3.46 & \\
\hline & & & 2.47 & Quiet Study 2 & 3.47 & Control Room \\
\hline & & & 2.48 & ILS Resource Area & 3.48 & \\
\hline & & & 2.49 & Meeting 3 & 3.49 & \\
\hline & & & 2.5 & Meeting 4 & 3.5 & \\
\hline
\end{tabular}

The FM perspective for the MediaCityUK building involves an agreement that some of the FM tasks would be covered by the landlord, while the University would be responsible for the others. The proposed University FM model shows how it plans to draw on other bigger FM providers to carry out some service provisions for the MediaCity building because it can be an enormous task to achieve from the main campus.

The interviewee acknowledged that they did not have hands-on involvement with IT aspects of FM but oversees a small team in that area. However, they acknowledged that BIM can have great deal of benefits and efficiency gains for FM service provisions on the condition that the BIM model incorporates the right information required for FM.

\section{FM Challenges for the University Building in MediaCityUK}

Information on the FM challenges was gathered from the MediaCity Director, who is also act- 
Figure 4. The concept map captures the related issues of FM and BIM

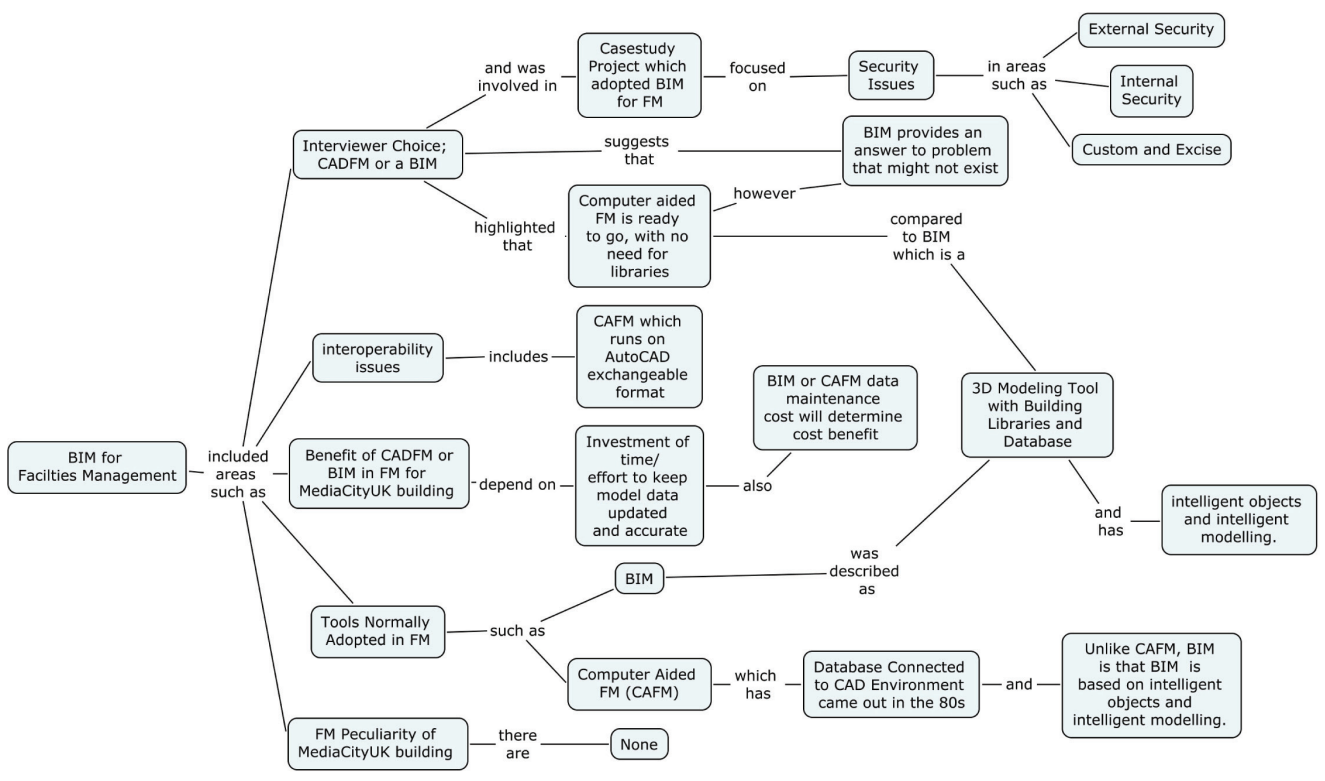

Figure 5. The concept map captures the related issues of VR and BIM

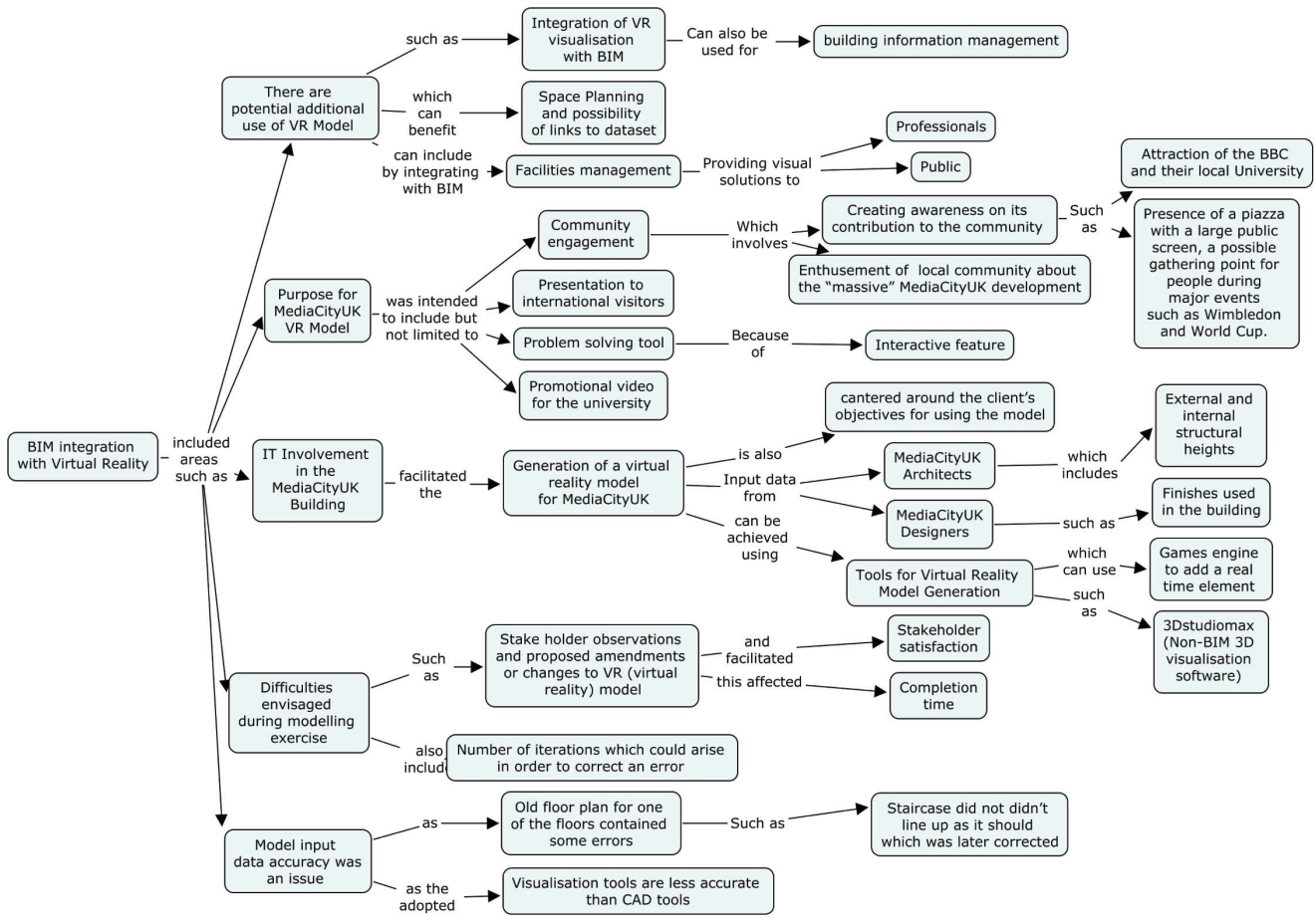


ing in the MediaCity Project on behalf of the university. The interviewee highlighted that the MediaCityUK buildings are actually owned by the contracting company and the University of Salford is one of the tenants. As a result, the contracting company legally has certain FM responsibilities for some of the Hard FM issues, which include the exterior fabric of the building, lifts and plants that service the general area. The concept map in Figure 7, which is developed from the findings of interview with the Mediacity director, captures the FM challenges for the university building in Mediacity.

The university will occupy the first four floors of 14 floors of the MediaCity building. Some of the tasks forming the criteria for the FM service specification are security, reception, catering. The interviewee also implied that the FM model adopted in the main university campus may not be extended or adopted for the university building in MediaCity. During university hours, the student services department will be responsible for the FM services, whereas the FM company will run the FM services outside those hours; it even though efforts are being made to make it a self service.

\section{Overall Analysis of Interview Findings}

Varying views and experiences with regard to possible challenges and BIM benefits to FM of the university building in MediaCity are revealed from the interviews. For example, the advance notification to the building users can help minimisation of disruptions during the move.

The data maintenance concern was also highlighted by the interviewees. For example, the interviewee who had expertise in FM implied resistance to the BIM implementation for FM and emphasised that well maintained CAFM software would deliver the IT requirements on FM in addition to CAFM being much older and a more familiar tool within the industry than BIM. This however, is arguable as other interviewees highlighted that the implementation of BIM within the FM industry would provide a lot more benefit, especially if integrated with VR. Furthermore, projects such as FM of Sydney Opera House (SOH) and Atlantic College (Morris et al., 2006), which employed BIM for the FM service provision, shows that BIM can be more beneficial for FM practice than CAFM. The concept map in Figure 8 shows the overall views and key issues from the interviews.

From the best practice projects and interviews conducted it became clear that the BIM model can offer FM benefits. However, the choice of adopting BIM for FM still requires that facility managers gain a level of awareness of its added benefits over the status quo, i.e., CAFM. The interviewees raised the issue of user knowledge, capacity building for the BIM adoption in FM, which should not be overlooked. Thus, the need to assess the potential holistic cost of adopting the BIM tool should incorporate user training. However, all the interviewees agreed that the BIM technology presents a valid potential for the cost saving both for the FM activities as long as data is accurate and well maintained.

\section{BIM Model Experimentation for FM in MediaCityUK}

The BIM model revealed a zoning character which was mirrored in the ground and first floor. The central east/west axis on plan view was reinforced with the studio functional spaces (TV studio B, TV studio store and TV studio A), and to the north were living spaces and an open plan area to the south. The Concept Map in Figure 9 shows the key issues in the BIM experimentation.

The studios were designed to have double volumes extending to the first floor. The double volume extension and studio function of these spaces suggests light/heavy studio equipments/ furniture that could affect the PM scheduling of access into TV studio A and TV studio B. Major accesses into the building were limited to the ground floor east, west and north sides, which becomes an important factor when scheduling the movement of furniture into the open plan area. However, the BIM model re- 
Figure 6. The concept map captures the challenges and Insight of FM for the university

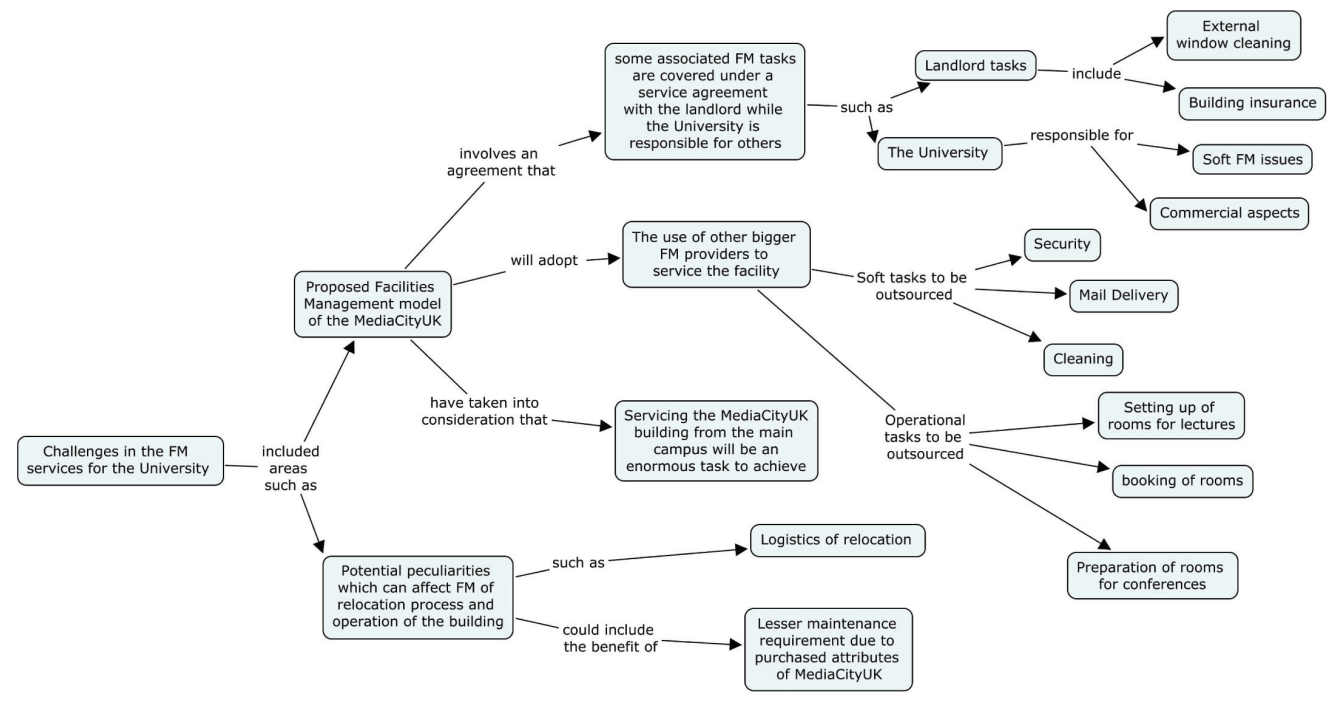

Figure 7. The concept map captures the FM challenges for the university building in MediaCity

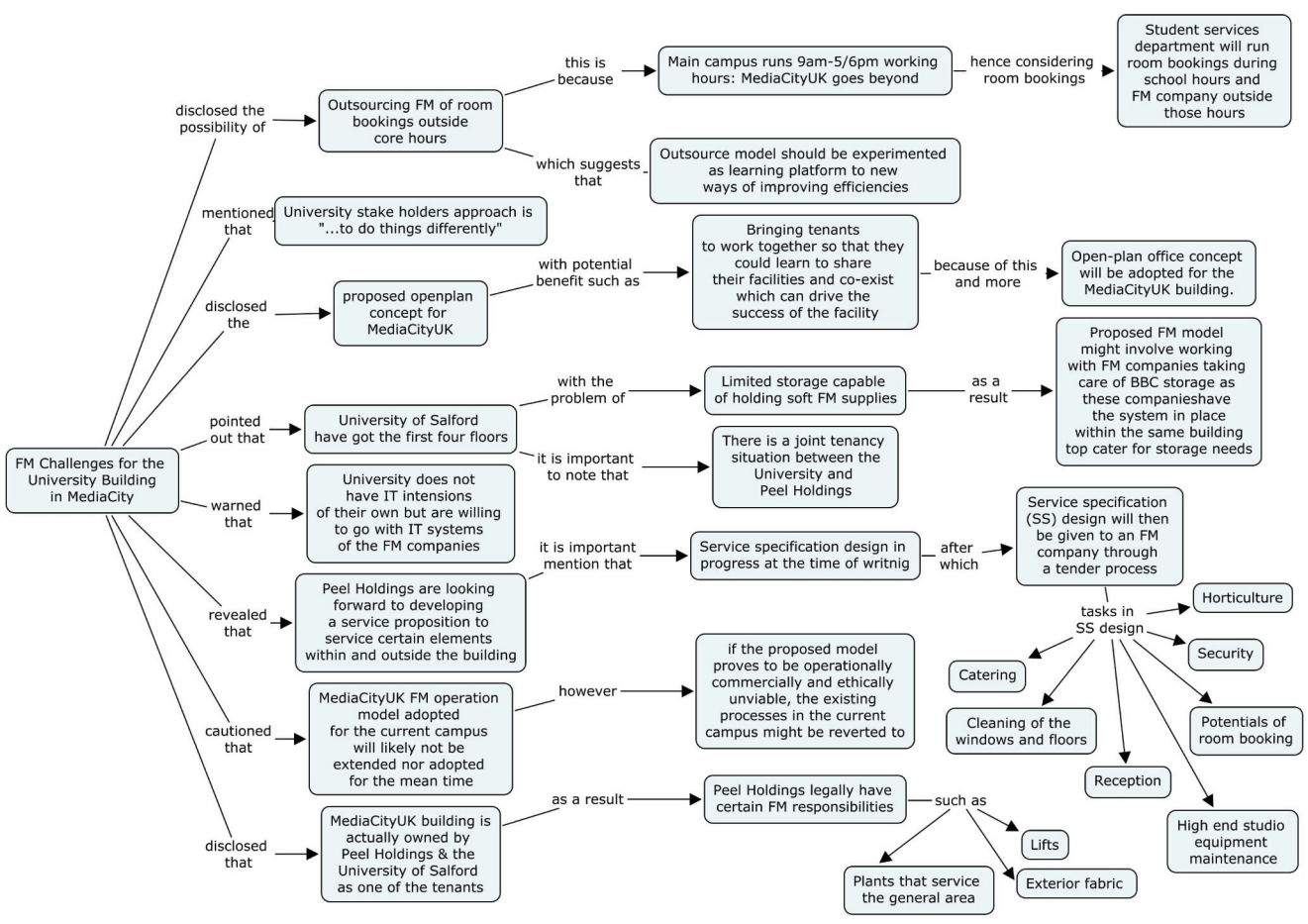


Figure 8. The concept map depicts an overview of the key issues from the interviews

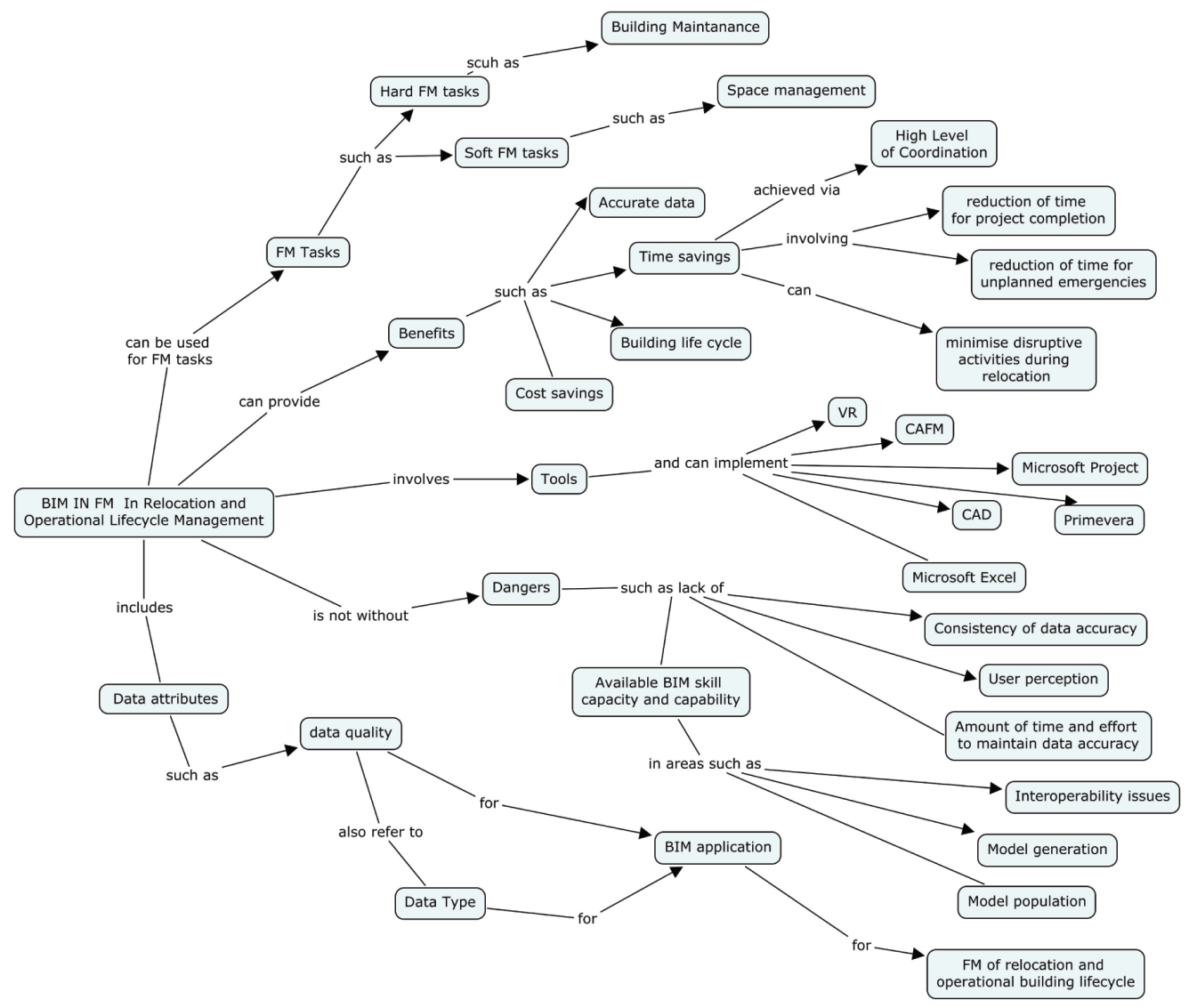

vealed that the open plan area can be populated but each item has to be dismantled to the minimum door dimension to fit the primary and secondary access double doors.

Areas like the north east part of the BIM model on the ground floor that is an open area with Living Laboratory and exhibition has a height that extends to the first floor resembling a mezzanine floor and a foot bridge from the mezzanine floor to the east/west axis of the building. This area will require accurate programming to populate with furniture and a good knowledge of the electrical points is crucial as increased human traffic is expected within this space.

At the second and third floors, the furniture distribution density from the BIM model based on drawings, were significantly higher than that in the ground and first floors. This suggests a significant amount of vertical transport. The contributions of BIM to FM maintenance operations and space management were further systematically analysed via BIM experimentation. In the following sub-sections, experimentation of the BIM model is elaborated against the key FM tasks.

\section{Analysis of BIM Benefits in the Relocation and Building Lifecycle FM}

Analysis of BIM benefits for relocation and building lifecycle FM is conducted in two categories. These are soft issues and hard issues in FM. 
Figure 9. Concept map illustrates the key issues in the BIM experimentation

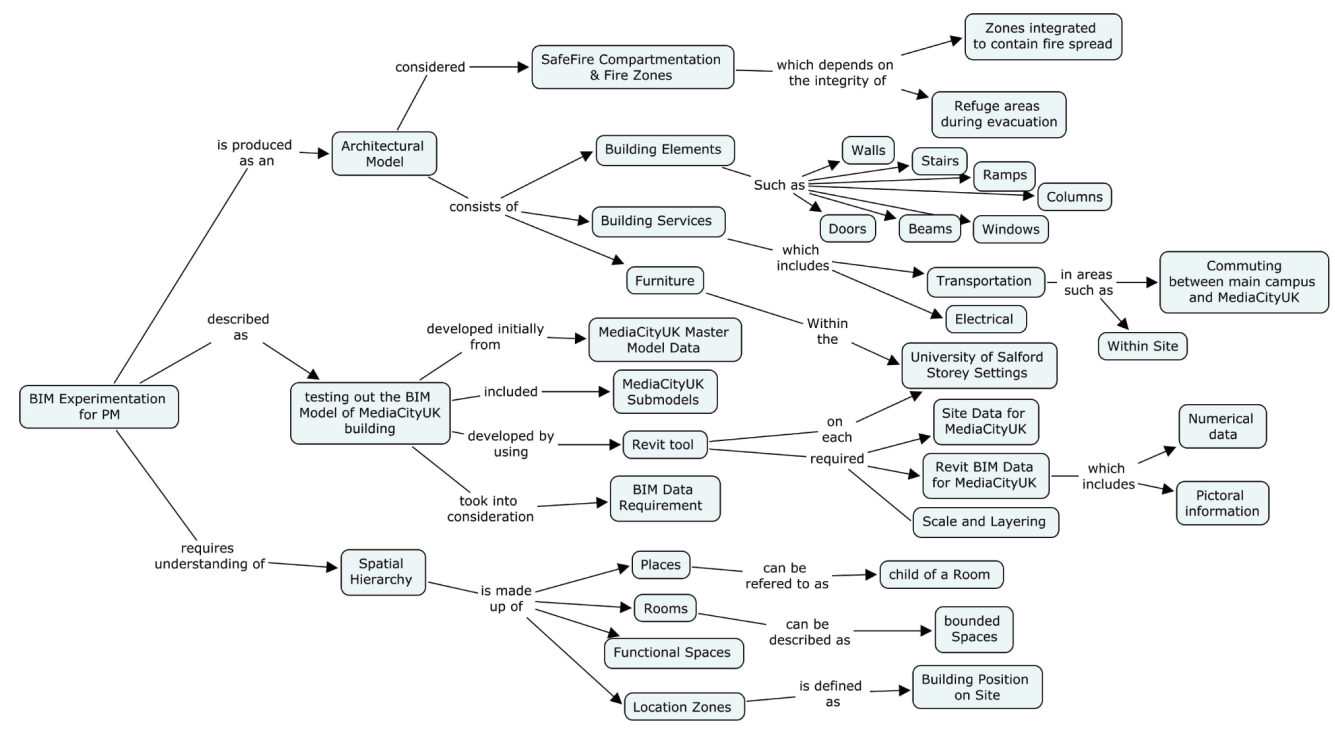

1. FM Soft Task 1: Office Space Management: Audit of space utilization, space re-designs. Flexible working and on-going space utilization management: In regard to relocation, the capability of BIM for storing and retrieving information used in construction brings the added advantage of spatial information management during the relocation process. This is achieved through the BIM model's ability to relay spatial information in 2D and 3D. The 3D immersive image alone will result in a limited FM value of the model. However, the presence of the database (backend) attached to the 3D geometry in BIM will not only allow for visual appreciation of designated function of each space, but will also help space identification using data fortified walkthroughs, which can result in more efficient furniture placement and also provide the parametric information required for on-site FM decision making during relocation such as security.

During the building operational life cycle, the crucial issue with regards to space management becomes the space utilization model.
The adopted/experimental space use model for the MediaCityUK by the University is that of flexible living open plan where active and passive interaction are encouraged and seclusion discouraged. As such it will be required that the above spatial experimentation during the operational cycle of the building be monitored to determine its impact on the building and occupants. Under this circumstance, the parameters to observe are the i) space planning (space functions and relationship of one space to another), ii) space preparation that involves setting up rooms for lectures, booking rooms, preparation of rooms for conferences, can be improved by applying the BIM scheduling capabilities, iii) spatial assessment to check for things like furniture placement and positions via iterations. At intervals during the operational life of the building rearrangement and replacement of furniture might become necessary. BIM model under a well managed information database can provide information on the number and types of furniture, if and when they are due for change.

2. FM Soft Task 2: Cleaning: During the operational life of the building, the entire 
fabric of the building will require some form of maintenance. The doors, windows, floors, will require cleaning from time to time. The BIM model being a data fortified prototype of the actual building will have the benefit of showing building elements that require cleaning. The data attached to each element will provide information of the cleaning status and the manufacturers cleaning specification.

3. FM Soft Task 3: Waste disposal and recycling: During the building's life cycle, the type of waste will involve smaller waste of time over a period. The BIM model can ensure that waste disposal will be coordinated between departments where possible in order to improve efficiency; appropriately planned and timed so as to reduce waste disposal time. This can be achieved by setting up the average waste expected per functional space, room or place as viewed in the BIM interface into the BIM database. These values can be calculated over a period of time which helps monitoring the waste disposal.

4. FM Soft Task 4: Reception: during the relocation, visitors are cautiously looked after for health and safety reasons, therefore BIM can only help to specify hazardous spaces and secured pathways in the building during the relocation based on which safety guidance can be updated regularly as the building interior will be a dynamic environment changing regularly. When the building is fully operational, the reception becomes a strategic interface between visitors and users with a workload including answering visitors' inquiries, directing visitors to their destinations, sorting and handing out mail, answering incoming calls on multi-line telephones or, a switchboard, setting appointments, filing, records keeping, keyboarding/data entry. This list of duties involves communication data storage and good real-time knowledge of spaces in the building and its updated functions. The BIM model being a prototype of the building with datasets for each space will constitute a strategic tool for the receptionist to increase functional efficiency.

5. FM Soft Task 5: Security: Security during the relocation will be more focused on activities involved with the move. This form of security will include protecting equipment and goods present during the relocation rather than operational equipment and personnel as the building is not expected to have resumed function. The BIM model as a result is expected to be of little benefit. During the operational life of the building there is full occupancy and functions, the building security workload is increased for a protracted period of time. Under such circumstances, BIM becomes a very effective tool and provides a way of seeing and identifying security breaches by instant visualisation of the 3D spaces.

6. FM Soft Task 6: IT/Switchboard: During the relocation, the BIM model provides significant value. For example, for IT installations, the BIM model, which has valuable information on each space, electrical sockets telecommunication points, will help in facilitating the relocation and the identification of space types. When the building is operational, the FM task of IT/switchboard management requires less work except for major maintenance works.

7. FM Soft Task 7: Calculating and comparing costs for the required goods or services to achieve maximum value for money: BIM can be used to identify what goods or services are required from its inventory. When the building becomes operational, BIM can be used to provide accurate inventory information on goods and services when populated regularly.

8. FM Soft Task 8: Managing and leading change to ensure minimum disruption to core activities: The adopted open-plan space use strategy for the MediaCityUK building is experimental and there is a possibility of change in the use of space. Under such circumstance, the need for efficient change management becomes crucial. BIM is capable of providing a single, consistent 
and up-to-date view of all aspects of the facility; hence it can be used to provide vital information to avoid conflict in operation during change. Furthermore, the visual information is crucial also to help streamline people and equipment traffic to eliminate confusion.

9. FM Soft Task 9: Coordinating and leading a team or teams of staff to cover various areas of responsibility: The BIM model with its parametric and spatial information helps identify functional spaces, rooms and places. This is very important during the building's operational lifecycle because there will be a significant number of staff members in the building, the BIM model can provide information on the building spaces, fabric and quantities.

10. FM Soft Task 10: Using performance management techniques to monitor and demonstrate achievement of agreed service levels and to lead on improvement: In order to monitor achievement of service levels the building needs to be operational, which will involve both personnel and building information. The BIM model is not capable of simulating the techniques and the set goals. However, the BIM model through its rich database and visualization capabilities can provide information that will help make the goals clearer and making obvious areas that needs improvements.

11. FM Soft Task 11:Responding appropriately to emergencies or urgent issues as they arise: Emergencies can come in various forms and issues vary. At the operational stage of the building, handling emergencies can be enhanced by the use of BIM. For example, a regular damage can be via a handrail that comes up against a place or pulled out of the wall. Under such or similar circumstance, the BIM model is able to provide information on the type of damage and the location of the damage. In the event of a fire emergency, the BIM $3 \mathrm{D}$ model is able at a glance to identify all available fire exits and refuge areas which could be used to inform and guide the occupants to a safe exit. However, if the emergency is medical, the BIM model only provides information about the building such as location of medical/first aid facilities, nearest access for ambulance and not the nature of the medical condition.

12. FM Soft Task 12: Directing and planning essential central services such as reception, security, maintenance, mail, archiving, cleaning, catering, waste disposal and recycling: Directing and planning essential listed central services at this level is purely management and can take place before, during and after the relocation. The importance of the BIM model in directing and planning essential central services would depend on how much investment of time and effort on keeping the model live and real. If this is the case, directing and planning the soft and hard tasks will benefit significantly from BIM.

Contribution of BIM to Hard FM issues in the relocation to and operation of the university building in MediaCity is elaborated below.

1. FM Hard Task 1: Maintenance of normal power systems (Electrical substations) and emergency power: When considering the maintenance of the power systems for the MediaCityUK building, as the BIM model includes information rooms and spaces, the building room or positions can be identified and accessed for the power equipments, including the positions of emergency lighting units and accessing their maintenance log from the BIM schedule. However, if the BIM model includes relevant engineering information, it can provide supports for facilities managers and relevant engineers such as manufacturing engineers for the maintenance of the building.

2. FM Hard Task 2: Maintenance of Building Automation System (BAS), security and locks: During the relocation and operational lifecycle of the building, it is important to ensure that the locks work properly. The importance is underscored by the move- 
ment of furniture and equipments which can be vulnerable to theft. The BIM model has a schedule which has the description, location, number and condition of every single lock in the building. This information will enable the FM staff to accurately identify the description, location, condition/manual of faulty locks and place order for a quick replacement. This approach can be applied to other security components of the building.

3. FM Hard Task 3: Maintenance of sprinkler systems, smoke/fire detection systems and fire extinguishers, signage and evacuation plans: information related to operational building lifecycle about the location description, location, condition of the sprinkler systems, smoke/fire detection systems and fire extinguishers, signage can be established in the BIM model. Therefore, it becomes easier to identify location of faulty sprinkler systems. For example, while a CAFM software enables users to report faulty equipments, further information and location of the equipment can be quickly retrieved from the BIM model and actioned promptly. The spatial data in BIM model will provide an invaluable visual and numerical information system that can help in deciding where to position fire extinguishers and signage.

4. FM Hard Task 4: Maintenance of Mechanical and Engineering (M\&E engineering): Maintenance of M\&E for the operational life cycle stage of the building can be carried out without a BIM model. However, if BIM model is used, which includes the M\&E components and information of each component stored in the database within the BIM model; it becomes very effective and efficient to respond to faults that may arise. For example, if there is a burst pipe in the MediaCityUK building, referring to the model to retrieve information about the burst pipe and visually assessing how the burst pipe will affect other pipe work and the rest of the building becomes a strong facilitator of the appropriate response. The
BIM model also provides similar information for the electrical system.

5. FM Hard Task 5: Maintenance of windows and doors: The BIM model database can create records of window/door fixes and replacements that can help identify patterns. The extent of any damage can be stored in the BIM model database against its model replica. Information on the history of the component retrieved from BIM and perceived damage can help decide if the solution is to fix it or call for a replacement.

6. FMHard Task 6: Checking that agreed work by staff or contractors has been completed satisfactorily and following up on any deficiencies: For the operational life of the building, as an FM task, assessing for satisfactory completion of works carried out by staff or contractor of the MediaCityUK can only derive value from BIM if the works involve the building fabric. For example, BIM's accurate geometrical representation of the parts of a building in an integrated data environment can provide useful information with which to compare and assess the completed job.

\section{SUMMARY AND CONCLUSION}

The paper has explored the extent how BIM could support the effective and efficient conduct of FM tasks using the university building in MediaCityUK. It shows that BIM provides support for the aforementioned FM tasks. For example, the instant walkthroughs generated from the BIM model assist FM in having a virtual tour of the building to visually assess key considerations during relocation. Furthermore, automated quantification and scheduling capability helps in setting cost and time targets such as the development and confirmation of budget. Moreover, its accurate quantification and scheduling attribute provides detailed information on number and types of furniture to be moved and other cost intensive decision making considerations. 
The BIM model as a prototype of the actual building provides information on the equipment, furniture, access routes within the building, safety systems. The use of BIM for maintenance operations of the MediaCityUK building will depend very much on how the model is populated, the available information on electrical, M\&E, and machinery/plant issues within the model and how this information in the model is maintained over time. If this is the case, the BIM model serves as the virtual replica of the building with important information on the maintenance histories of each component within the building.

In the event of a maintenance problem, e.g., in the plumbing system, the BIM model can provide visual information on the location of the fixture, how the fixture relates to other fixtures and the building as a whole, where the fixture type have been used in other areas of the building in order to inspect for potential damage. Such information makes it easier for the FM team to identify and rectify. The BIM benefit in this regard is dependent on the type, quantity and quality of information within the model.

However, it will not be economically viable to adopt the BIM approach such as for relatively small projects as it requires high information quality and extensive training of its users may be required, which can compromise the time and cost savings from BIM use.

Overall, the MediaCityUK building is made up of open plan areas/functional spaces, closed spaces/rooms and spaces which extend vertically to the next floor/voids. In 2D representation, these spaces become difficult to understand and articulate with regards to its designated use. With ordinary 3D CAD representations, the spaces can be visually appreciated with no specification details and quantities attached. However, during decision making on space use, the designer/FM representative need to convey proposed ideas to the stakeholder or client both visually and technically in order enable them to make a visually and technically informed decision on space use. On the other hand, BIM enables the FM manager to identify spaces, its uses, the wall/building component that the space is made of, how one space relates to another, what within a space can potentially inhabit its function such as a high-level wall projection in a high traffic corridor.

\section{REFERENCES}

Arayici, Y., Coates, P., Koskela, L., Kagioglou, M., Usher, C., \& O'Reilly, K. (2011). Technology adoption in the BIM implementation for lean architectural practice. International Journal of Automation in Construction, 20(2), 189-195. doi:10.1016/j.autcon.2010.09.016

Azhar, S., Nadeem, A., Mok, J. Y. N., \& Leung, B. H. Y. (2008, August 4-5). Building Information Modelling (BIM): A new paradigm for visual interactive modelling and simulation for construction projects. In Proceedings of the First International Conference on Construction in Developing Countries: Advancing and Integrating Construction Education, Research \& Practice, Karachi, Pakistan (pp. 435-446).

Cardellino, P., \& Finch, E. (2006). Evidence of systematic approaches to innovation in facilities management. Journal of Facilities Management, 4(3), 150-166. doi:10.1108/14725960610673742

Cotts, D., Roper, K. O., \& Payant, R. P. (2009). The facility management handbook. New York, NY: AMACOM.

CRC. (2007). Adopting BIM for facilities management: Solutions for managing Sydney Opera House. CRC Construction Innovation, Australia. Retrieved from http://www.construction-innovation.info

Gillard, A., Counsell, J. A. M., \& Littlewood, J. R. (2008). The Atlantic College case study - Exploring the use of BIM for the sustainable design and maintenance of property. Paper presented at the Construction and Building Research Conference of the Royal Institution of Chartered Surveyors COBRA.

Jordani, A. J. (2010). BIM and FM: The portal to lifecycle facility management. Journal of Building Information Modeling, 13-16.

Jordani, D. (2008). BIM: A healthy disruption to a fragmented and broken process. Journal of Building Information Modelling, 24-26.

Kymell, W. (2008). Building information modeling: planning and managing construction projects with $4 D$ CAD and simulations. New York, NY: McGraw-Hill. 
Mitchel, J. (2005). Sydney Opera House case study - FM exemplar project (Research Report No. 2005001-C-3). Retrieved from http://www.constructioninnovation.info/index 3 ca5.html?id=53

Mohd Noor, M. N., \& Pitt, M. (2009). A critical review on innovation in facilities management service delivery. Facilities, 27(5-6).

Morris, J., Ballesty, S., Ding, L., Drogemuller, R., Mitchell, J., Schevers, H., et al. (2006). An integrated collaborative approach for FM-Sydney Opera House FM exemplar. In Proceedings of the 2nd International Conference of the CRCfor Construction Innovation, Sydney, Australia (pp. 1-13).

NBIMS.(2007). National building information model standard version 1.0 - Part 1: Overview, principles, and methodologies. National Institute of Building Sciences, Washington. Retrieved from http://www. facilityinformationcouncil.org/bim/publications.php
Okeil, A. (2010). Hybrid design environments: Non-immersive architectural design. Journal of Information Technology in Construction, 15, 202-216.

Olomolaiye, A., Liyanage, C. L., Egbu, C. O., \& Kashiwagi, D. (2004). Knowledge management for improved performance in facilities management. Paper presented at the International Construction Research Conference of the Royal Institution of Chartered COBRA.

Rundell, R. (2006). How can BIM benefit facilities management? Primeedge. Retrieved from http:// www.cadalyst.com/cad/building-design/1-2-3-revitbim-and-fm-3432

Russell, V. (2009). BBC signs MediaCity UK deal. Retrieved from http://www.business-services.salford.ac.uk/cms/news/article/?id=3

Wylie, I. (2007). First view of the BBC Media City. Manchester Evening News.http://menmedia.co.uk/ news/s/237141_first_view_of_the_bbc_media_city 